7th International Symposium on Superalloy 718 and Derivatives Edited by: E.A. Ott, J.R. Groh, A. Banik, I. Dempster, T.P. Gabb, R. Helmink, X. Liu, A. Mitchell, G.P. Sjöberg, and A. Wusatowska-Sarnek TMS (The Minerals, Metals \& Materials Society), 2010

\title{
CAST ALLOYS FOR ADVANCED ULTRA SUPERCRITICAL STEAM TURBINES
}

\author{
Gordon R. Holcomb, ${ }^{1}$ Paul D. Jablonski, ${ }^{1}$ Ping Wang, ${ }^{1,2}$ \\ ${ }^{1}$ National Energy Technology Laboratory, 1450 Queen Avenue SW, Albany, OR 97321 \\ ${ }^{2}$ URS Corp, PO Box 618, South Park, PA 15129
}

Keywords: Advanced Ultra Supercritical, Steam Turbine, Superalloy, Casting, Homogenization, Oxidation, Haynes 263, Haynes 282, Nimonic 105

\begin{abstract}
The proposed steam inlet temperature in the Advanced Ultra Supercritical (A-USC) steam turbine is high enough $\left(760{ }^{\circ} \mathrm{C}\right)$ that traditional turbine casing and valve body materials such as ferritic/martensitic steels will not suffice due to temperature limitations of this class of materials. Cast versions of three traditionally wrought Ni-based superalloys (Haynes 263, Haynes 282, and Nimonic 105) were evaluated for use as casing or valve components for the next generation of industrial steam turbines. The full size castings are substantial: $2-5,000 \mathrm{~kg}$ each half and on the order of $100 \mathrm{~mm}$ thick. Experimental castings were quite a bit smaller, but section size was retained and cooling rate controlled to produce equivalent microstructures. A multi-step homogenization heat treatment was developed to better disperse the alloy constituents. These castings were subsequently evaluated by characterizing their microstructure as well as their steam oxidation resistance (at 760 and $800^{\circ} \mathrm{C}$ ).
\end{abstract}

\section{Introduction}

Goals of the U.S. Department of Energy's Advanced Power Systems Initiatives include power generation from coal at $60 \%$ efficiency, which requires steam conditions of up to $760{ }^{\circ} \mathrm{C}$ and 35 $\mathrm{MPa}$, so called Advanced Ultra Supercritical (A-USC) steam conditions [1]. Higher efficiency will translate to reduced $\mathrm{CO}_{2}$ production for the same amount of energy produced, thereby facilitating a reduction in green house gas emissions, or if combined with carbon capture and sequestration, there will be less $\mathrm{CO}_{2}$ to capture and sequester. General usage of the terms subcritical, supercritical (SC), ultra-supercritical (USC), and A-USC for coal power plants is as follows: subcritical at below $22 \mathrm{MPa}$, SC at above $22.1 \mathrm{MPa}$ and 538 to $565{ }^{\circ} \mathrm{C}$, USC at above $565{ }^{\circ} \mathrm{C}$, and A-USC above temperatures where nickel base superalloys must be used, $\sim 675{ }^{\circ} \mathrm{C}$ [1]. Nickel base superalloys are required in A-USC conditions due to high temperature creep strength requirements in these pressurized systems.

Cast versions of Ni-based superalloys are needed for use as casing or valve components for AUSC steam turbines. The full size castings are substantial: 2-5,000 kg each half and on the order of $100 \mathrm{~mm}$ thick. The large component sizes combined with the high strengths of the alloys makes fabrication by forging impractical. Traditionally wrought alloys were selected due to their superior weldability, especially in thick sections.

These cast nickel alloys must also possess excellent steam oxidation resistance because these components must last for a minimum of 20 years in A-USC steam power plants. The research presented here evaluates the steam oxidation resistance of three cast and homogenized alloys, 
based on Haynes 263 (H263), Haynes 282 (H282), and Nimonic 105 (N105), in comparison with wrought commercial versions of the same alloys. The experimental castings were quite a bit smaller than the turbine components, but section size was retained and cooling rate controlled to produce equivalent microstructures. A multi-step homogenization heat treatment was developed to better disperse the alloy constituents to reduce segregation and improve mechanical performance.

The materials used in the research will be discussed with emphasis on the techniques used to fabricate the cast and homogenized alloys. Then the experimental techniques used to expose the alloys to steam at 760 and $800{ }^{\circ} \mathrm{C}$ will be provided with the results presented in terms of oxidation kinetics and resulting microstructures. The paper will conclude with a discussion on the merits of each of the three cast alloys as a structural material in A-USC steam conditions.

\section{Materials}

Three alloys are the focus of the research. The cast alloys are based on H263, H282, and N105. The nominal and actual alloy compositions are shown in Table I.

Table I. Nominal and Actual Alloy Compositions (wt\%)

\begin{tabular}{|c|c|c|c|c|c|c|c|c|c|c|c|c|}
\hline Alloy & $\mathrm{Ni}$ & $\mathrm{Cr}$ & Co & Mo & $\mathrm{Ti}$ & $\mathrm{Al}$ & $\mathrm{Fe}$ & $\mathrm{Mn}$ & $\mathrm{Si}$ & $\mathrm{C}$ & $\begin{array}{c}\mathrm{B} \\
\mathrm{ppm}\end{array}$ & Other \\
\hline \multicolumn{13}{|c|}{$\mathrm{H} 263$} \\
\hline $\begin{array}{c}\text { Nominal } \\
{[2]}\end{array}$ & $\mathrm{Bal}$ & $\begin{array}{l}19- \\
21\end{array}$ & $\begin{array}{l}19- \\
21\end{array}$ & $\begin{array}{c}5.6- \\
6.1\end{array}$ & $\begin{array}{l}1.9- \\
2.4\end{array}$ & $0.6^{*}$ & $0.7^{*}$ & $0.6^{*}$ & $0.4^{*}$ & $\begin{array}{c}0.04- \\
0.08\end{array}$ & & \\
\hline Cast & $\mathrm{Bal}$ & 19.68 & 19.89 & 5.74 & 2.04 & 0.4 & & 0.5 & 0.35 & & & \\
\hline Wrought & Bal & 19.92 & 20.09 & 5.68 & 2.12 & 0.36 & 0.04 & 0.47 & 0.28 & 0.09 & & S 0.0002 \\
\hline \multicolumn{13}{|c|}{$\mathrm{H} 282$} \\
\hline $\begin{array}{c}\text { Nominal } \\
{[3]}\end{array}$ & Bal & $\begin{array}{l}18.5- \\
20.5\end{array}$ & $\begin{array}{l}9- \\
11\end{array}$ & $\begin{array}{l}8- \\
9\end{array}$ & $\begin{array}{l}1.9- \\
2.3\end{array}$ & $\begin{array}{l}1.38- \\
1.65\end{array}$ & $1.5^{*}$ & $0.3^{*}$ & $0.15^{*}$ & $\begin{array}{c}0.04- \\
0.08\end{array}$ & $\begin{array}{c}30- \\
50\end{array}$ & \\
\hline Cast & Bal & 19.22 & 9.84 & 8.48 & 2.08 & 1.44 & & 0.24 & 0.15 & 0.07 & 100 & \\
\hline Wrought & $\mathrm{Bal}$ & 19.30 & 10.12 & 8.51 & 2.13 & 1.36 & 0.15 & 0.08 & 0.03 & 0.07 & 40 & S 0.0002 \\
\hline \multicolumn{13}{|c|}{ N105 } \\
\hline $\begin{array}{c}\text { Nominal } \\
{[4]}\end{array}$ & Bal & $\begin{array}{l}14.0- \\
15.7\end{array}$ & $\begin{array}{l}18.0- \\
22.0\end{array}$ & $\begin{array}{c}4.5- \\
5.5\end{array}$ & $\begin{array}{l}0.9- \\
1.5\end{array}$ & $\begin{array}{c}4.5- \\
4.9\end{array}$ & $1.0 *$ & $1.0^{*}$ & $1.0^{*}$ & $0.17 *$ & $\begin{array}{l}30- \\
100\end{array}$ & 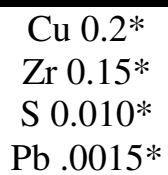 \\
\hline Cast & Bal & 14.61 & 20.04 & 5.02 & 1.10 & 4.43 & & 0.51 & 0.51 & 0.16 & 500 & \\
\hline Wrought & $\mathrm{Bal}$ & 15.40 & 19.75 & 5.09 & 1.21 & 4.27 & 0.43 & 0.08 & 0.12 & 0.15 & 48 & S 0.0001 \\
\hline
\end{tabular}

* Maximum

The alloys are listed in Table I in order of increasing strength and decreasing weldability. This is largely due to the amount of gamma prime developed in each alloy resulting from additions of Al and Ti. As can be seen in the table, the amount of both elements increase as one progresses down the table resulting in $\sim 7$ weight percent gamma prime in $\mathrm{H} 263, \sim 17$ weight percent gamma prime in $\mathrm{H} 282$ and $~ 36$ weight percent gamma prime in N105.

Each of the alloys was cast with a nominal superheat of $50{ }^{\circ} \mathrm{C}$ above the liquidus into a $100 \mathrm{~mm}$ diameter mold to emulate the slow cooling in the full scale casting. After casting and sampling for chemistry, each was subjected to a computationally optimized homogenization heat treatment 
[6-7]. This was important because the castings were found to be inhomogeneous due to nonequilibrium solidification resulting in localized regions poor in $\mathrm{Cr}$ and $\mathrm{Al}$ (potentially impacting oxidation resistance) as well as $\mathrm{Al}$, $\mathrm{Ti}$ and Mo (potentially impacting strength). Post homogenization the castings were given their recommended aging heat treatment. The effectiveness of the homogenization cycle was evident in the microstructure [6] as well as in the creep performance [8] which was found to be comparable to the wrought versions of the alloys.

All of the cast and homogenized alloys were peak aged prior to oxidation testing. The wrought $\mathrm{H} 282$ and N105 alloys were also peak aged prior to oxidation testing. The wrought H263 was solution annealed.

\section{Oxidation}

The steam oxidation resistance of the cast and homogenized alloys, in comparison with wrought alloys, was measured by exposing coupons of each alloy to steam at 760 and $800{ }^{\circ} \mathrm{C}$. The coupons were 1-2 $\mathrm{mm}$ thick and were polished to a 600 grit surface finish. The water used to produce the steam was deaerated with Argon prior to entering the furnace. The samples were removed for mass change determination after every 250 hours. Each time the samples were removed from the furnace, the furnace was allowed to cool over several hours prior to sample removal. Each time the samples were inserted into the furnace, the furnace was reheated at approximately $50{ }^{\circ} \mathrm{C}$ per hour. Some of the samples were removed from exposure testing after 1000, 2000, and in one case, 2500 hours of total time at temperature.

Scanning electron microscopy (SEM) was used to examine cross-sections of exposed samples, primarily with back-scattered electron (BSE) detection for compositional contrast (lighter elements appear darker, heavier elements appear brighter). Statistics of the amount of external scaling and internal oxidation were obtained from a series of 30 images, at magnifications ranging from $3000 \times$ to $7000 \times$, across one side of the cross-sectioned sample. In cases where magnification higher than 3000x was used (due to thinner scales requiring higher magnification to make accurate measurements), the next site was chosen by scrolling along the cross-section in the 3000x frame. Each 3000x frame was approximately $80 \mu \mathrm{m}$ across, so the statistics were gathered across approximately $0.24 \mathrm{~cm}$ of surface $(30 \times 80 \mu \mathrm{m})$. At each of the 30 locations, the thickness of external scale and depth of internal oxidation were measured at consistent locations relative to each image. The maximum observed depth of internal oxidation in the image was also recorded.

Also of interest were differences in grain boundary precipitates between the cast and homogenized alloys compared with their wrought analog. Scanning electron microscopy of grain boundaries in the interior of the samples, well away from the surface, was performed both prior to steam exposure and after steam exposure, to differentiate between those microstructural features inherent to the casting from those due to steam oxidation exposure.

\section{Results and Discussion}

Oxidation results, in terms of mass change kinetics, are shown in Fig. 1. For H263 and H282, there were no significant differences between the cast and homogenized material and the wrought alloys. This is in contrast to N105, where the cast and homogenized material exhibited much greater mass gains than the wrought versions of the same alloy. 
$760{ }^{\circ} \mathrm{C}$
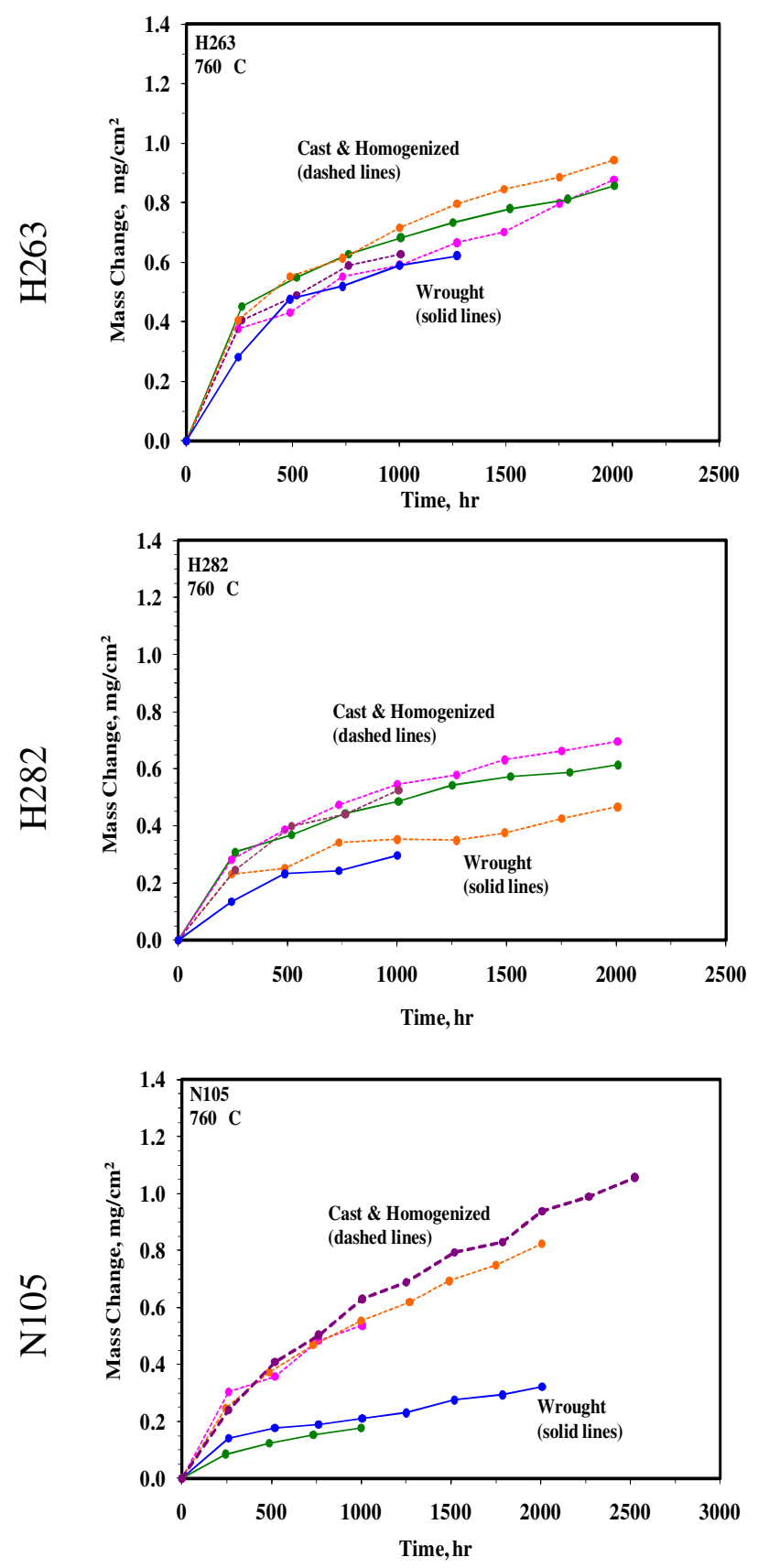

$800{ }^{\circ} \mathrm{C}$
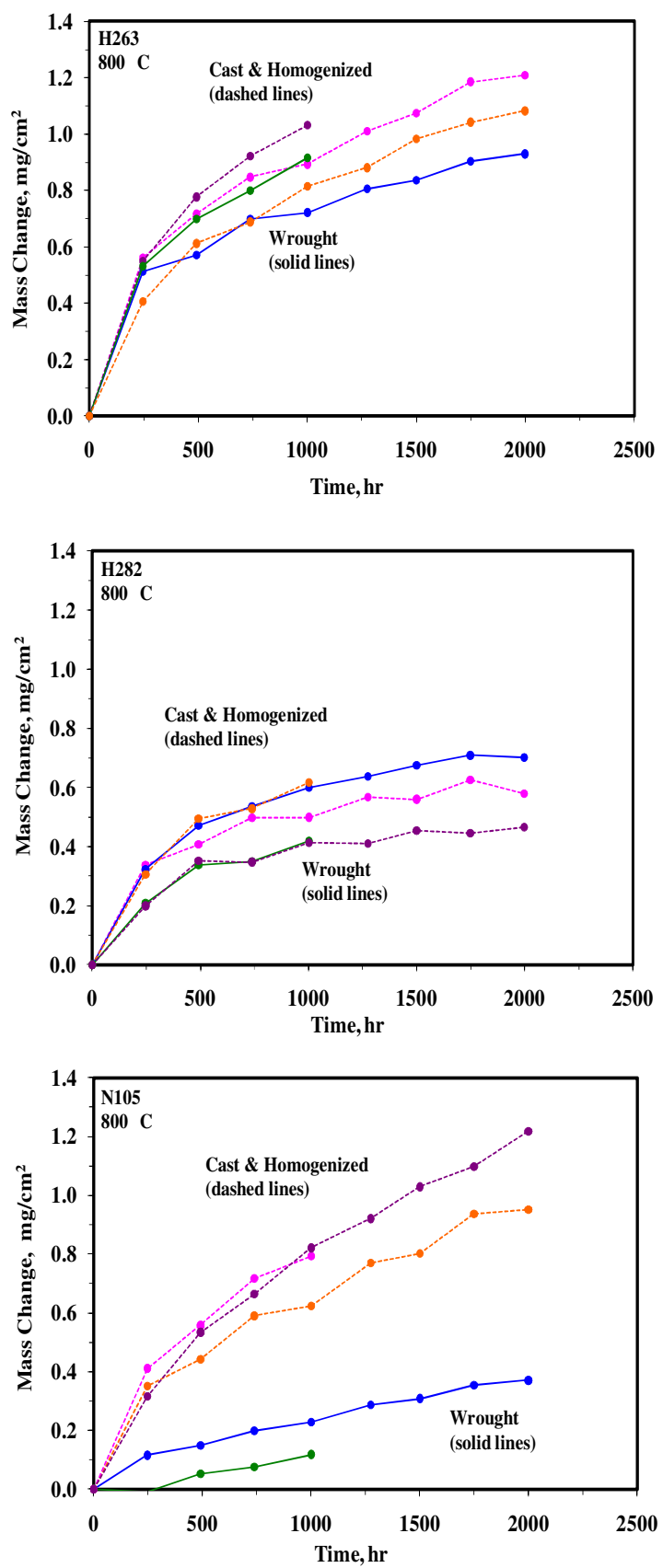

Figure 1. Mass change results after exposure to steam.

The data in Fig. 1 was fitted to parabolic rate kinetics using Eq. 1, where $\mathrm{k}_{\mathrm{p}}$ is the parabolic rate constant, $\Delta \mathrm{M}$ is the mass change per unit area, and $\mathrm{t}$ is time.

$$
\mathrm{k}_{\mathrm{p}}=\frac{\Delta \mathrm{M}^{2}}{2 \mathrm{t}}
$$

In some cases the data fit parabolic kinetics better after an initial period of time than starting at $\mathrm{t}=0$. Initial oxidation may be non-parabolic [5], and excluding some of the initial mass change data can improve the determination of $\mathrm{k}_{\mathrm{p}}$. To quantify the decision to obtain $\mathrm{k}_{\mathrm{p}}$ after an initial 
period of time, the F-statistic (using the Linest function in Excel) was used. Each curve in Fig. 1 was examined with the F-statistic using all the data. Subsequently, all but the first data point $(0,0)$ was analyzed, then all but the first two data points, and so on, up to using just the final four data points. The data set with the maximum F-statistic was used to obtain $\mathrm{k}_{\mathrm{p}}$. The $\mathrm{k}_{\mathrm{p}}$ data are presented in Table II and are the weighted averages of the two or three curves for each condition in Fig. 1.

Table II. Parabolic Rate Constant Data

\begin{tabular}{cccccc}
\hline \multirow{2}{*}{ Alloy } & \multirow{2}{*}{ Version } & \multicolumn{2}{c}{ Average $\mathrm{k}_{\mathrm{p}}, \mathrm{mg}^{2} \mathrm{~cm}^{-4} \mathrm{hr}^{-1}$} & $\begin{array}{c}\text { Last } \mathrm{N} \\
\text { Points }\end{array}$ & $\begin{array}{c}\text { Last } \mathrm{N} \\
\text { Points } \\
\end{array}$ \\
\cline { 3 - 6 } & & $760{ }^{\circ} \mathrm{C}$ & $800{ }^{\circ} \mathrm{C}$ & $760{ }^{\circ} \mathrm{C}$ & $800{ }^{\circ} \mathrm{C}$ \\
\hline \multirow{2}{*}{$\mathrm{H} 263$} & Cast \& Homogenized & $1.67 \mathrm{E}-04 \pm 3.3 \mathrm{E}-05$ & $3.19 \mathrm{E}-04 \pm 1.3 \mathrm{E}-04$ & $5,9,9$ & $5,9,9$ \\
& Wrought & $1.30 \mathrm{E}-04 \pm 1.8 \mathrm{E}-05$ & $2.03 \mathrm{E}-04 \pm 1.3 \mathrm{E}-04$ & 6,9 & 5,9 \\
\multirow{2}{*}{$\mathrm{H} 282$} & Cast \& Homogenized & $9.35 \mathrm{E}-05 \pm 3.7 \mathrm{E}-05$ & $6.75 \mathrm{E}-05 \pm 7.2 \mathrm{E}-05$ & $5,9,9$ & $5,9,9$ \\
& Wrought & $6.69 \mathrm{E}-05 \pm 2.7 \mathrm{E}-05$ & $1.08 \mathrm{E}-04 \pm 2.7 \mathrm{E}-05$ & 5,9 & 5,9 \\
\multirow{2}{*}{$\mathrm{N} 105$} & Cast \& Homogenized & $1.88 \mathrm{E}-04 \pm 4.7 \mathrm{E}-05$ & $3.23 \mathrm{E}-04 \pm 7.7 \mathrm{E}-05$ & $5,9,11$ & $5,9,9$ \\
& Wrought & $1.63 \mathrm{E}-05 \pm 5.7 \mathrm{E}-06$ & $2.89 \mathrm{E}-05 \pm 2.2 \mathrm{E}-05$ & 5,9 & 4,9 \\
\hline
\end{tabular}

In Table II the "Last N Points" columns show the extent of limiting the data set with the Fstatistic. The $1000 \mathrm{hr}$ test periods had a maximum of 5 data points and the $2000 \mathrm{hr}$ test periods had a maximum of 9 data points (the value at a time of 0 and then 4 or $8250 \mathrm{hr}$ time increments). A few tests ran longer and so have a higher number of data points. The F-statistic analysis resulted in only one data point being eliminated from the analysis - the 0 time point for one of the wrought N105 tests. The number of data points were also used as a weighting factor (along with the standard deviation) to obtain average $\mathrm{k}_{\mathrm{p}}$ values, as shown in Eq. 2.

$$
\text { average } \mathrm{k}_{\mathrm{p}}=\frac{\sum_{\mathrm{i}=1}^{\mathrm{n}} \frac{\mathrm{N}_{\mathrm{i}} \mathrm{k}_{\mathrm{p}, \mathrm{i}}}{\sigma_{\mathrm{i}}^{2}}}{\sum_{\mathrm{i}=1}^{\mathrm{n}} \frac{\mathrm{N}_{\mathrm{i}}}{\sigma_{\mathrm{i}}^{2}}}
$$

In Eq. 2, $\mathrm{n}$ is the number of oxidation samples (or lines in Fig. 1) grouped together to be averaged.

In terms of microstructural differences, Figs. 2-4 show the cross-sections of H263, H282, and N105, respectively, after 1000 hours of steam exposure. For H263 in Fig. 2, external chromia scales with internal oxidation of $\mathrm{Ti}$ and $\mathrm{Al}$ were observed in every case. The internal oxidation was more pronounced (deeper and thicker) in the cast and homogenized alloys than in the wrought alloys, and was more extensive at $800{ }^{\circ} \mathrm{C}$ than at $760{ }^{\circ} \mathrm{C}$. Similar results were found for H282 in Fig. 3.

For N105 in Fig. 4, the cast and homogenized samples developed a chromia scale with extensive internal oxidation of Al and Ti. For wrought N105, there were two types of structures foundone with a similar chromia external scale with internal oxidation of $\mathrm{Al}$ and $\mathrm{Ti}$, and one with a very thin alumina external scale. This was true even at $800{ }^{\circ} \mathrm{C}$ even though Fig. 4 only shows the chromia scale region. Alumina scales are much more protective of the base alloy and result 
in less mass gain than chromia scales. Thus the differences in oxidation kinetics seen in Fig. 1 for N105 result from a significant fraction of the surface being protected by an alumina scale.

The differences in microstructures seen in Figs. 2-4 are quantified in Table III. For H263, the external scales (cast and homogenized verses wrought) are similar in terms of average thickness and standard deviation. Internal oxidation is generally more pronounced in the cast and homogenized alloys than in the wrought alloys, both in terms of average values (with the exception of $1000 \mathrm{hr}$ at $760{ }^{\circ} \mathrm{C}$ ) and maximum depth observed.

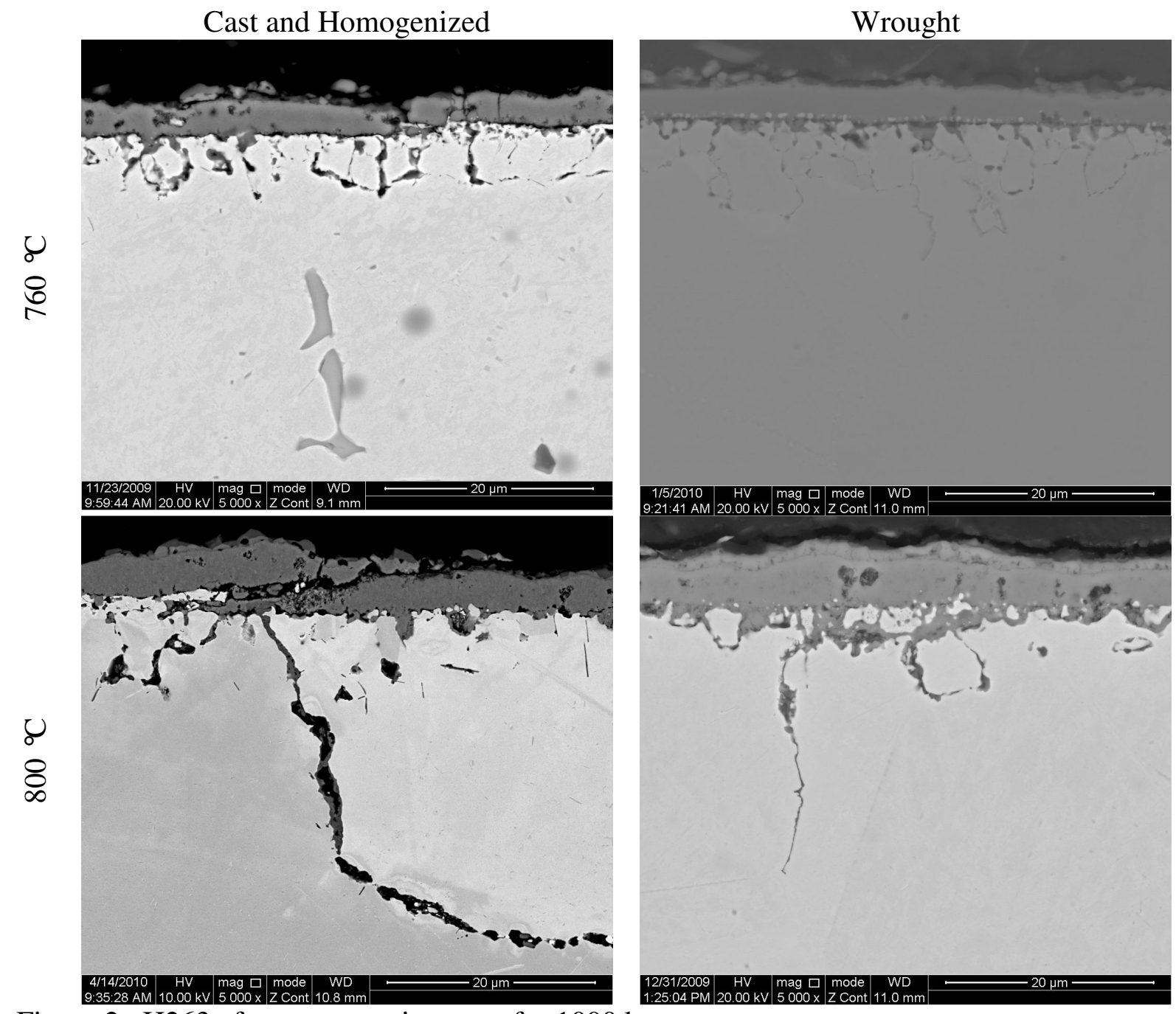

Figure 2. H263 after exposure in steam for $1000 \mathrm{hr}$.

Table III for H282 shows thicker external scales and deeper internal oxidation (both in terms of the average and maximum depth observed) in the cast and homogenized alloys than in the wrought alloys.

Table III for wrought N105 shows much more variation (in terms of the standard deviation percentage, std \%) than any of the other alloys for both external scales and internal oxidation. This is consistent with Fig. 4 and the observation of regions with very protective and thin alumina scales and some regions with thicker chromia scales and internal oxidation. The thickness of the external scale and the depth of internal oxidation grew quite rapidly with time, more than doubling in thickness with a doubling of exposure time. This indicates that the areas 
protected by alumina external scales were shrinking with time. To support this, Fig. 5 shows the internal oxidation measurements after 1000 and 2000 hours after they have been ordered from smallest to largest and displayed in a probability plot. With time the curves for each temperature shift more to the left (less alumina coverage) than they shift upwards (internal oxidation depth increasing). This could be indicative of insufficient transport of Al to the surface to maintain the alumina scale. At these temperatures, grain boundary diffusion would predominate over lattice diffusion and would be grain size dependant. The cast and homogenized alloys have much larger grain sizes than the wrought alloys and this would explain why the external alumina scales did not develop on them.
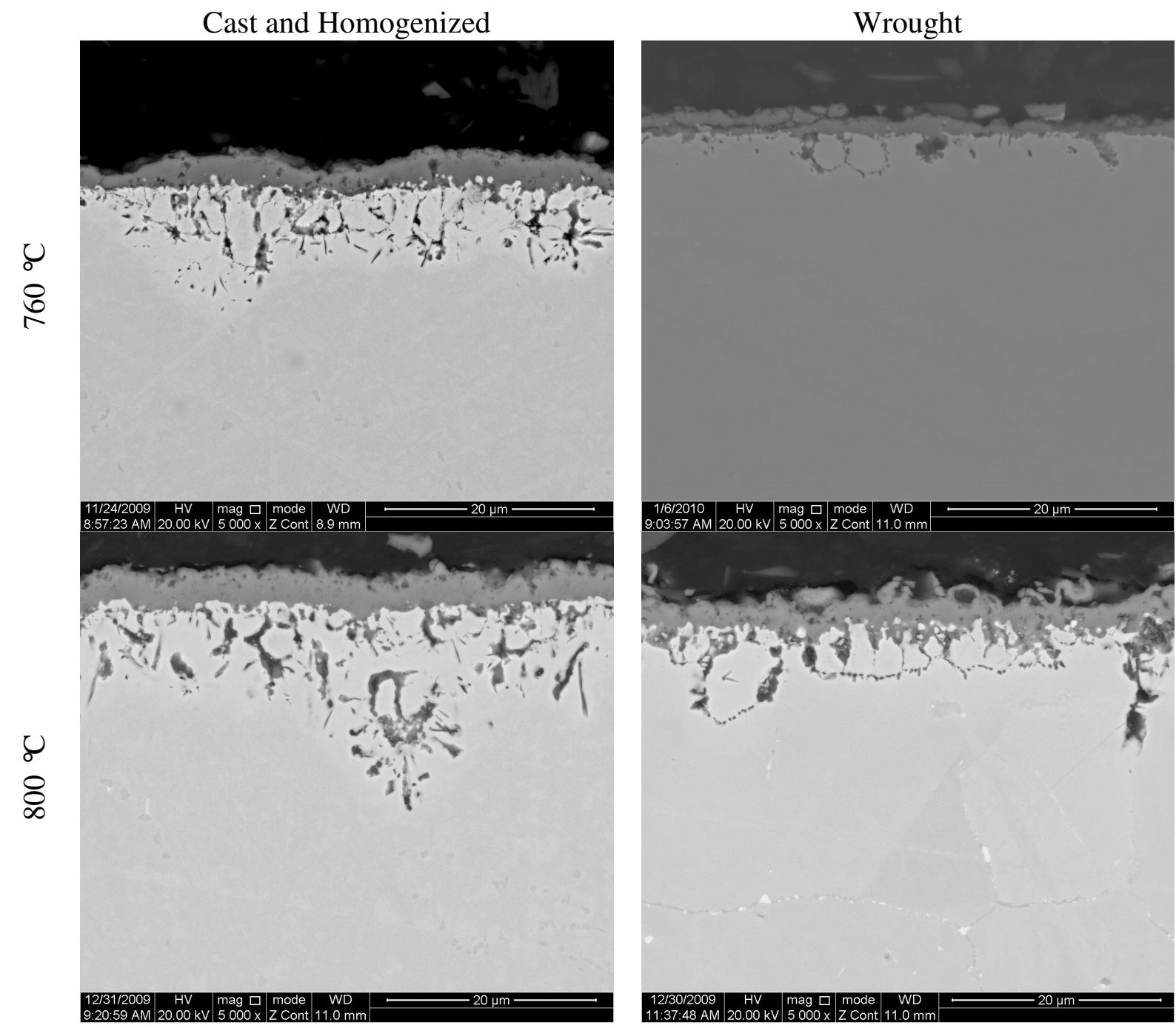

Figure 3. H282 after exposure in steam for $1000 \mathrm{hr}$.

Table III for the cast and homogenized N105 shows very small standard deviation for internal oxidation, indicating that the depth of internal oxidation is rather uniform. In all cases the cast and homogenized N105 showed more external scaling and internal oxidation than the wrought N105.

Differences between the cast and homogenized alloys, compared with wrought alloys, go beyond grain size differences. Figures 6-8 show the internal microstructures of H263, H282, and N105, respectively, both before and after 1000 hours of steam exposure at $800{ }^{\circ} \mathrm{C}$. 
In Fig. 6 for H263, aging for 1000 hours at $800{ }^{\circ} \mathrm{C}$ resulted in increased grain boundary precipitation. The aged grain boundaries are decorated with light and dark precipitates. Energydispersive $\mathrm{x}$-ray spectroscopy (EDS) indicated that the light precipitates were Mo-rich carbides and the dark precipitates were $\mathrm{Cr}$-rich carbides. The precipitates were too small to get accurate compositional chemistries beyond these general chemistry indications. The amount of precipitates on the cast and homogenized grain boundaries was much greater than those formed on the wrought grain boundaries. This is likely the result of the limited grain boundary area in the cast material as opposed to differences in chemistry between the wrought and cast versions (Table I).
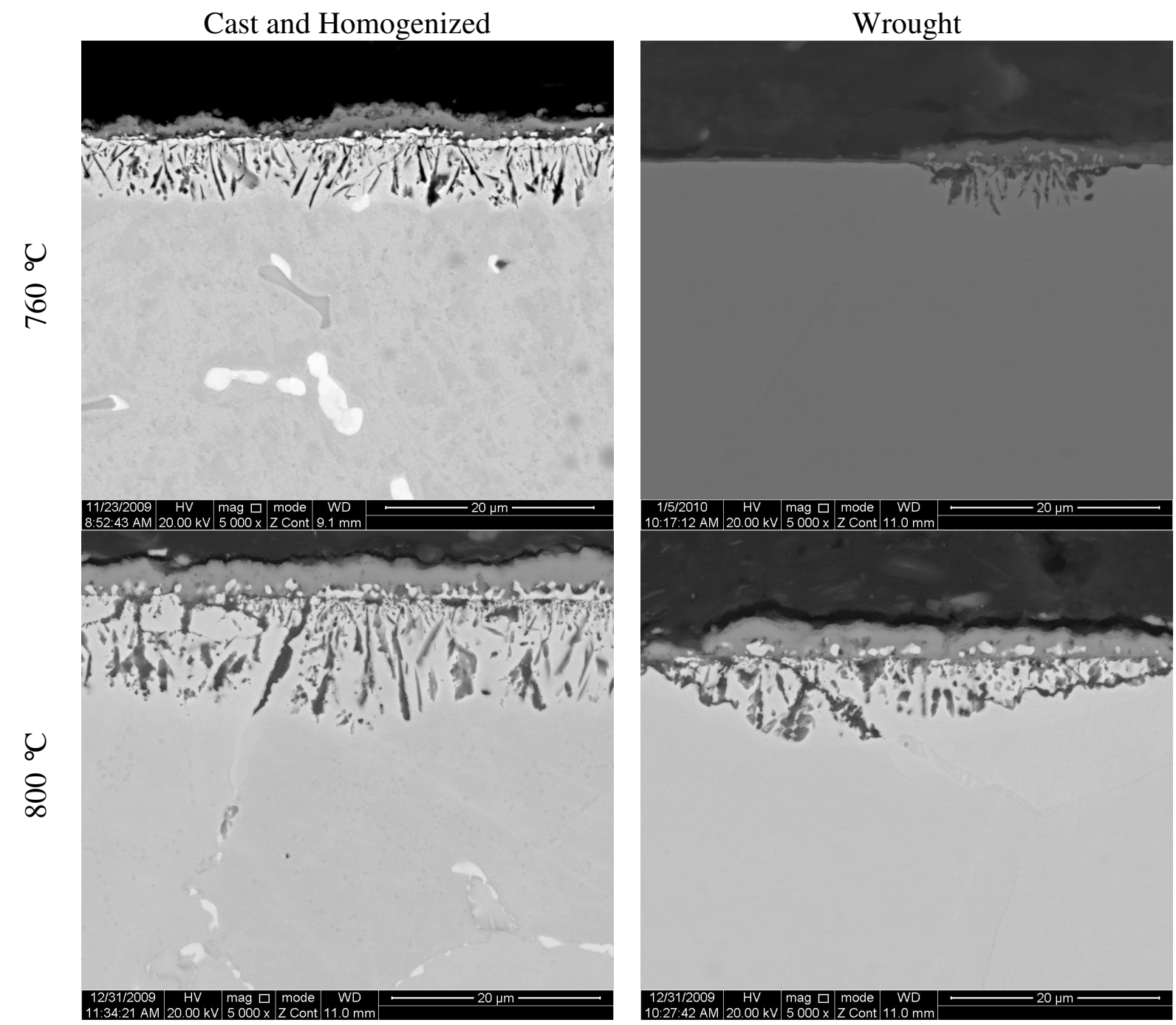

Figure 4. N105 after exposure in steam for $1000 \mathrm{hr}$.

In Fig. 7 for $\mathrm{H} 282$, aging produced little difference in grain boundary precipitates. The light precipitates were again Mo-rich carbides. In cast $\mathrm{H} 282$, the larger dark precipitates were Ti-rich carbides. The smaller dark precipitates (and the precipitates in the cast and homogenized sample) were $\mathrm{Cr}$-rich carbides. Aging did induce the formation of very fine precipitates within the grains. 
In Fig. 8 for N105, aging produced little differences in either grain boundary precipitates or within the grain. The cast and homogenized grain boundaries contained light Mo-rich carbides and dark Ti-rich and Cr-rich carbides. Only dark Cr-rich carbides were observed on the wrought N105 grain boundaries.

Table III. External Scale and Internal Oxidation Behavior

\begin{tabular}{|c|c|c|c|c|c|c|c|c|}
\hline \multirow{2}{*}{\multicolumn{2}{|c|}{ Alloy }} & \multirow{2}{*}{$\begin{array}{l}\mathrm{T} \\
{ }^{\circ} \mathrm{C}\end{array}$} & \multirow{2}{*}{$\begin{array}{l}\mathrm{T} \\
\mathrm{hr}\end{array}$} & \multicolumn{2}{|c|}{ External Scale } & \multicolumn{3}{|c|}{ Internal Oxidation } \\
\hline & & & & $\begin{array}{c}\text { Thickness } \\
\mu \mathrm{m}\end{array}$ & std \% & $\begin{array}{c}\text { Thickness } \\
\mu \mathrm{m}\end{array}$ & std \% & $\begin{array}{c}\text { Maximum } \\
\mu \mathrm{m}\end{array}$ \\
\hline \multirow{8}{*}{$\begin{array}{l}\text { ֶુ } \\
\text { İ } \\
\end{array}$} & \multirow{4}{*}{$\tilde{\tilde{U}}$} & 760 & 1000 & $2.81 \pm 0.63$ & $22 \%$ & $4.70 \pm 4.08$ & $87 \%$ & 28.20 \\
\hline & & 760 & 2000 & $3.34 \pm 0.97$ & $29 \%$ & $9.79 \pm 5.35$ & $55 \%$ & 42.62 \\
\hline & & 800 & 1000 & $3.95 \pm 0.83$ & $21 \%$ & $9.36 \pm 5.63$ & $60 \%$ & 63.75 \\
\hline & & 800 & 2000 & $5.32 \pm 1.46$ & $27 \%$ & $10.37 \pm 4.14$ & $40 \%$ & 79.38 \\
\hline & \multirow{4}{*}{$\begin{array}{l}\overrightarrow{7} \\
\\
000 \\
0 \\
0 \\
3 \\
3\end{array}$} & 760 & 1000 & $2.79 \pm 0.37$ & $13 \%$ & $7.11 \pm 3.49$ & $49 \%$ & 16.44 \\
\hline & & 760 & 2000 & $4.36 \pm 0.64$ & $15 \%$ & $5.18 \pm 2.68$ & $52 \%$ & 23.94 \\
\hline & & 800 & 1000 & $4.15 \pm 1.10$ & $26 \%$ & $3.83 \pm 1.81$ & $47 \%$ & 29.42 \\
\hline & & 800 & 2000 & $4.25 \pm 1.01$ & $24 \%$ & $4.28 \pm 2.86$ & $67 \%$ & 29.60 \\
\hline \multirow{8}{*}{$\begin{array}{l}\text { N } \\
\text { I } \\
\text { I }\end{array}$} & \multirow{4}{*}{ ש্ } & 760 & 1000 & $2.54 \pm 0.43$ & $17 \%$ & $6.92 \pm 3.73$ & $54 \%$ & 34.22 \\
\hline & & 760 & 2000 & $4.53 \pm 1.36$ & $30 \%$ & $6.26 \pm 4.73$ & $76 \%$ & 38.00 \\
\hline & & 800 & 1000 & $2.58 \pm 0.53$ & $21 \%$ & $10.33 \pm 5.00$ & $48 \%$ & 42.36 \\
\hline & & 800 & 2000 & $4.24 \pm 0.92$ & $22 \%$ & $12.45 \pm 4.49$ & $36 \%$ & 65.75 \\
\hline & \multirow{4}{*}{ 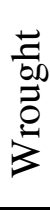 } & 760 & 1000 & $1.13 \pm 0.35$ & $30 \%$ & $1.81 \pm 1.07$ & $59 \%$ & 10.21 \\
\hline & & 760 & 2000 & $3.00 \pm 0.55$ & $18 \%$ & $5.09 \pm 2.20$ & $43 \%$ & 25.13 \\
\hline & & 800 & 1000 & $2.41 \pm 0.50$ & $21 \%$ & $5.59 \pm 3.07$ & $55 \%$ & 16.31 \\
\hline & & 800 & 2000 & $3.88 \pm 0.84$ & $22 \%$ & $9.23 \pm 3.54$ & $38 \%$ & 32.10 \\
\hline \multirow{8}{*}{$\frac{\mathfrak{o}}{z}$} & \multirow{4}{*}{$\overrightarrow{\tilde{U}}$} & 760 & 1000 & $1.52 \pm 0.50$ & $33 \%$ & $5.95 \pm 0.69$ & $12 \%$ & 9.90 \\
\hline & & 760 & 2000 & $2.86 \pm 0.81$ & $28 \%$ & $10.09 \pm 1.90$ & $19 \%$ & 17.58 \\
\hline & & 800 & 1000 & $3.66 \pm 0.67$ & $18 \%$ & $9.47 \pm 1.57$ & $17 \%$ & 14.25 \\
\hline & & 800 & 2000 & $5.77 \pm 0.97$ & $17 \%$ & $16.22 \pm 2.06$ & $13 \%$ & 42.00 \\
\hline & \multirow{4}{*}{ 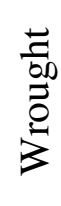 } & 760 & 1000 & $0.39 \pm 0.47$ & $119 \%$ & $0.60 \pm 1.22$ & $201 \%$ & 9.25 \\
\hline & & 760 & 2000 & $0.98 \pm 0.86$ & $89 \%$ & $2.46 \pm 2.75$ & $112 \%$ & 14.86 \\
\hline & & 800 & 1000 & $0.74 \pm 0.92$ & $125 \%$ & $1.24 \pm 2.08$ & $168 \%$ & 9.50 \\
\hline & & 800 & 2000 & $2.42 \pm 1.63$ & $68 \%$ & $3.24 \pm 3.17$ & $98 \%$ & 17.58 \\
\hline
\end{tabular}




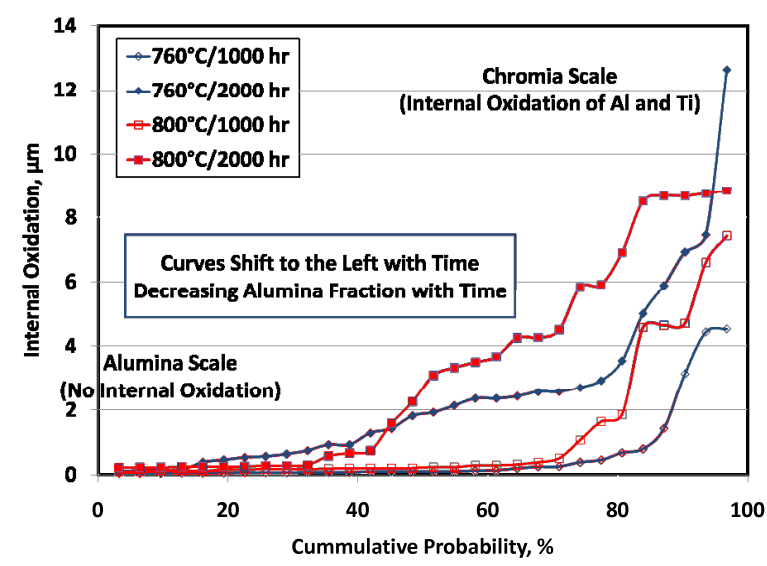

Figure 5. Probability plot of the internal oxidation found for wrought N105 after exposure in steam for 1000 and $2000 \mathrm{hr}$.

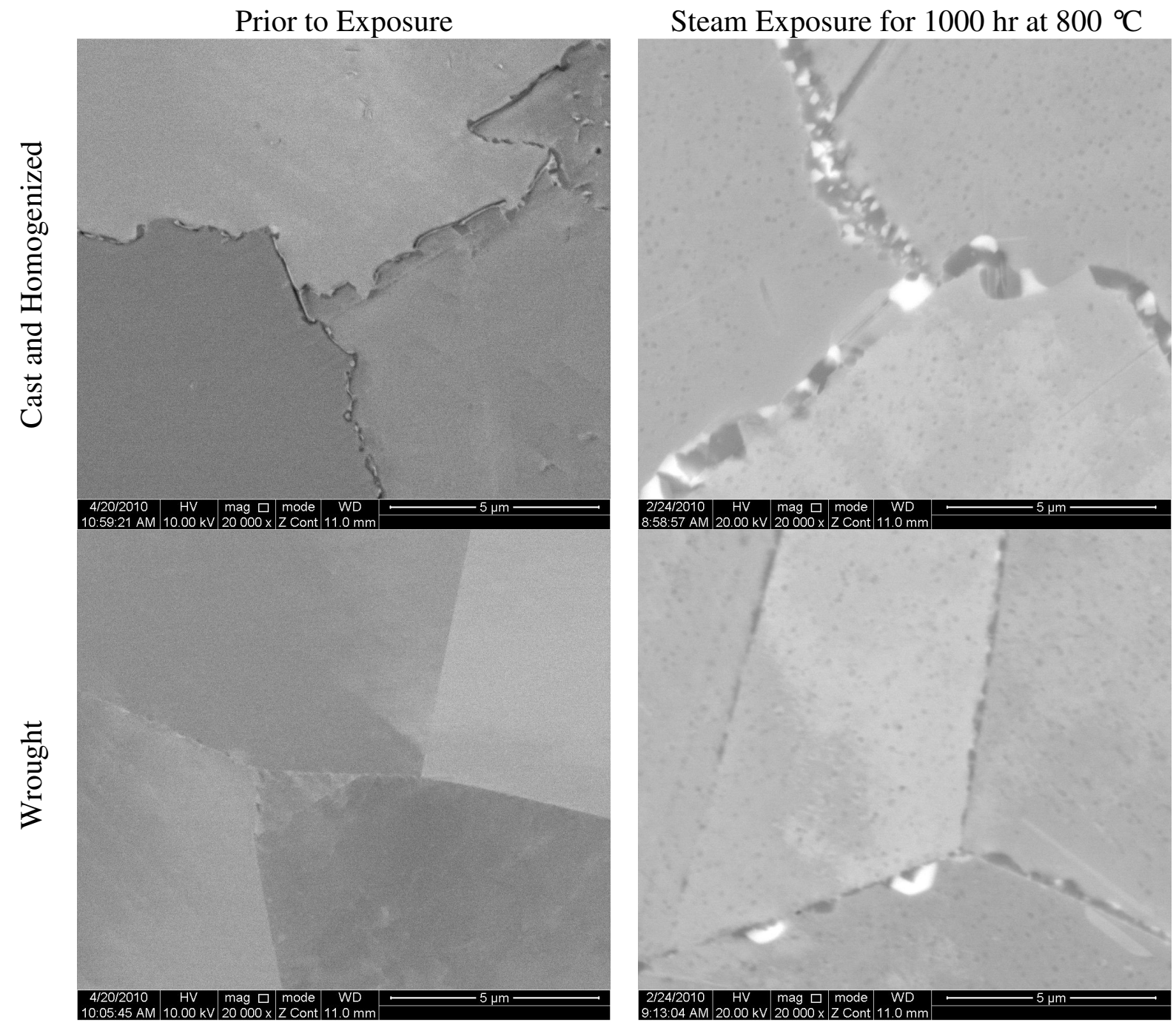

Figure 6. Comparison of grain boundary precipitation for H263.

The cast alloy creep results are compared to the typical wrought alloy performance in Fig. 9. The overall results of the three alloys fell in order of gamma prime content with N105 having the 
best creep performance followed closely by H282. For all three alloys, it was found that the cast versions performed comparably to their wrought counterparts. This is due in part to the homogenization heat treatment [6-7] given each alloy prior to peak aging. Without this heat treatment, critical strengthening elements such as $\mathrm{Al}$, Ti, and Mo would be concentrated either in the dendrite cores or interdendritic regions of the cast material. This cast structure is broken in wrought alloys up during ingot preheat and hot working operations. The effectiveness of the homogenization heat treatment is also apparent when comparing the microstructures of the cast to the wrought alloys (Figs. 6-8) which appear similar. Of course, another feature of the cast microstructure favoring creep performance is the large grain size.
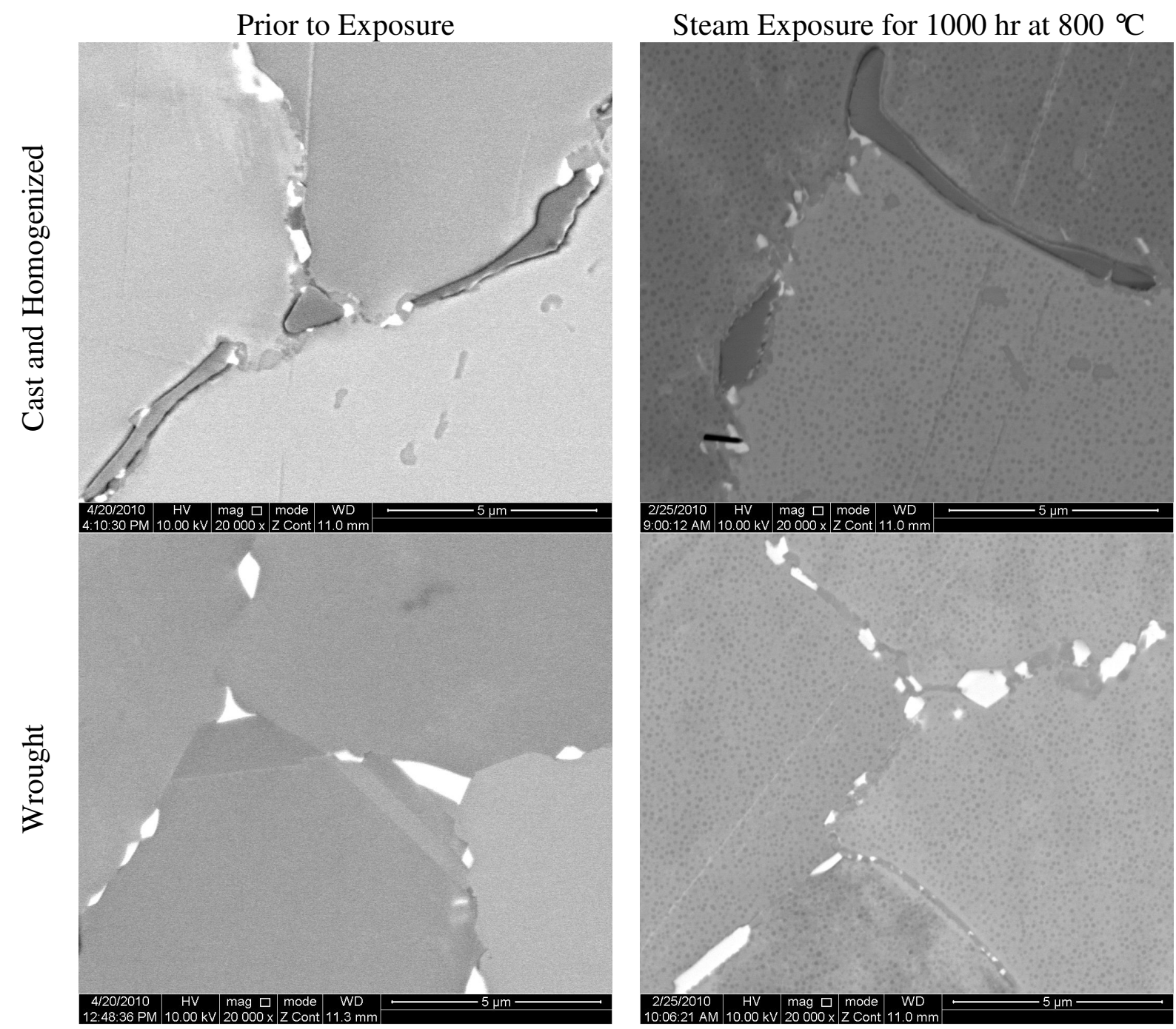

Figure 7. Comparison of grain boundary precipitation for $\mathrm{H} 282$. 


\section{Conclusions}

The development of high creep strength and steam oxidation resistant cast alloys for use in AUSC steam turbines is required to meet the need of some of the large components that comprise the turbine. Three wrought alloys, H263, H282, and N105, were selected for the development of cast versions through the use of advanced casting and homogenization heat treating procedures. The steam oxidation resistance of the cast and homogenized versions of these alloys was compared with commercial wrought versions of the alloys.

For H263, an external scale of chromia and internal oxidation of $\mathrm{Al}$ and $\mathrm{Ti}$ was found for both the cast and homogenized alloys and the wrought alloys. The overall mass gain and parabolic kinetics were similar. The depth of internal oxidation was greater in the cast and homogenized alloys. More Mo-rich and Cr-rich carbides were found along the grain boundaries of the cast and homogenized alloys.
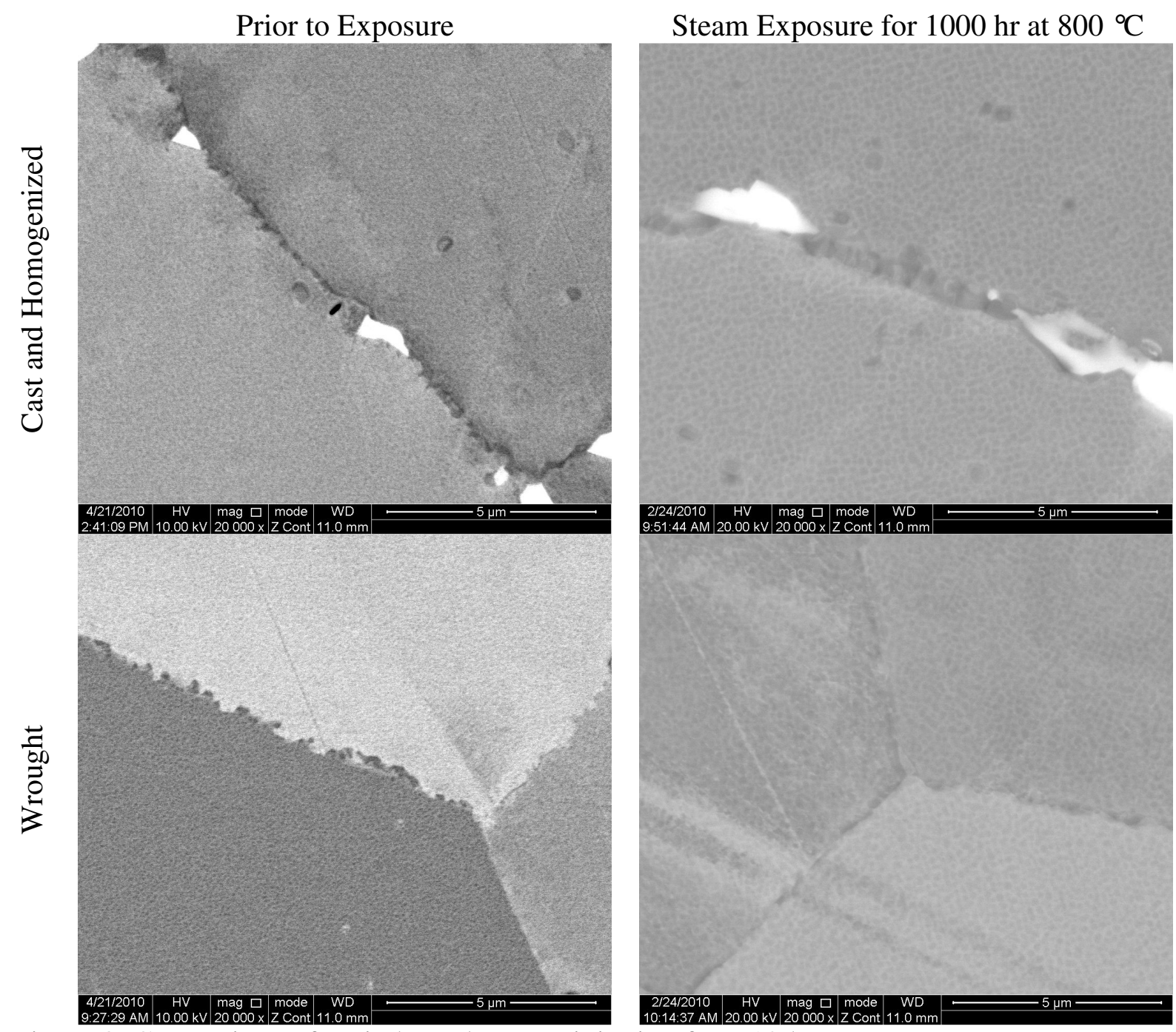

Figure 8. Comparison of grain boundary precipitation for N105. 


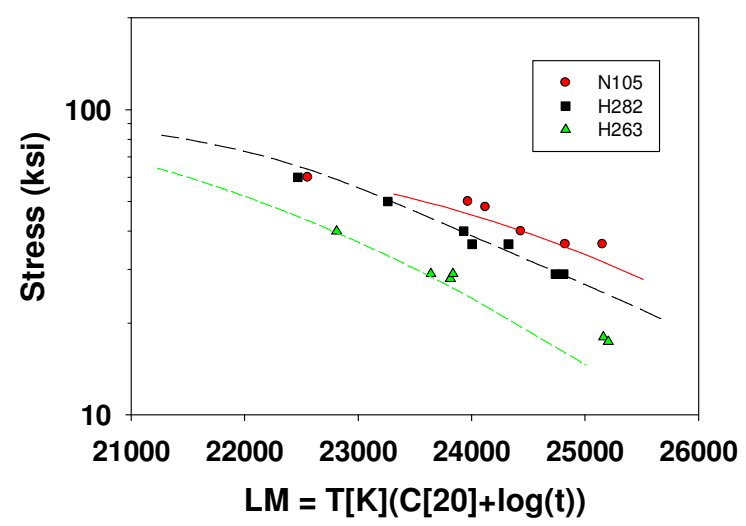

Figure 9. Comparison of the cast alloys (data points) to the average wrought alloy creep performance is shown in the plot above.

For $\mathrm{H} 282$ an external scale of chromia and internal oxidation of $\mathrm{Al}$ and $\mathrm{Ti}$ was found for both the cast and homogenized alloys and the wrought materials. The overall mass gain and parabolic kinetics were similar. The depth of internal oxidation was greater in the cast and homogenized alloys. More of both Mo-rich carbides and $\mathrm{Cr}$-rich carbides were found along the grain boundaries of the cast and homogenized alloys. In addition, Ti-rich carbides were found along the grain boundaries of the cast and homogenized alloys, which were not observed in the wrought alloys.

For N105 the wrought alloys exhibited lower oxidation kinetics than the cast and homogenized alloys. This occurred because some of the surface of the wrought alloys was covered by a very protective alumina scale. Where the alumina scale was not present, a chromia scale was present with internal oxidation of $\mathrm{Al}$ and $\mathrm{Ti}$ underneath it. The chromia scale and internal oxidation was found throughout the cast and homogenized alloys. The fraction of the surface protected by the alumina scale decreased with time. The cast and homogenized grain boundaries contained Morich carbides, Ti-rich carbides, and $\mathrm{Cr}$-rich carbides. Only the Cr-rich carbides were observed on the wrought N105 grain boundaries.

The creep performance of the cast alloys compared favorably with the averages for the respective wrought alloys with the ranking lining up with the levels of gamma prime content. The favorable level of cast alloy performance was likely due to the combined effect of the homogenization heat treatment given the alloys and the large grain size of the cast material.

\section{References}

1. R. Viswanathan et al., "U.S. Program on Materials Technology for Ultra-supercritical Coal Power Plants," Journal of Materials Engineering and Performance, 14 (3) (2005), 281-292.

2. Haynes International, "Haynes 263 Alloy" (H-3047D, Kokomo, IN: Haynes International, 2000).

3. Haynes International, "Haynes 282 Alloy" (H-3173, Kokomo, IN: Haynes International, 2008). 
4. Special Metals Corporation, "Nimonic Alloy 105" (SMC-081, Huntington, WV: Special Metals Corporation, 2007).

5. P. Kofstad, High Temperature Corrosion (New York, NY: Elsevier Applied Science, 1988), 132-161.

6. P.D. Jablonski and C.J. Cowen, "Homogenizing a Nickel-Based Superalloy: Thermodynamic and Kinetic Simulation and Experimental Results," Met. Trans. B, 40B (2009), 182-186.

7. P.D. Jablonski and C.J. Cowen, "Computationally Optimized Homogenization Heat Treatment of Metal Alloys," filed with the U.S. Patent office, August, 2009.

8. P.D. Jablonski et al., "Addressing Materials Processing Issues for Steam Turbines: Cast Versions of Wrought Ni-Based Superalloys" (Paper presented at the TMS Annual meeting, Seattle, Washington, 14-18 February 2010). 